\title{
Biomimetic Hydroxyapatite Coated Titanium Screws Demonstrate Rapid Implant Stabilization and Safe Removal In-Vivo
}

\author{
Jan Henrik Sörensen"1, Lutz Dürselen², Ken Welch ${ }^{3}$, Torben Christian Sörensen4, \\ Philip Procter $^{5}$, Håkan Engqvist', Maria Strømme ${ }^{3}$, Anita Ignatius ${ }^{2}$, Hartwig Steckel ${ }^{*}$ \\ ${ }^{1}$ Department of Pharmaceutics and Biopharmaceutics, Christian-Albrechts University, Kiel, Germany \\ ${ }^{2}$ Institute of Orthopaedic Research and Biomechanics, Centre of Musculoskeletal Research, Ulm, Germany \\ ${ }^{3}$ Division for Nanotechnology and Functional Materials, The Ångström Laboratory, Uppsala University, Uppsala, \\ Sweden \\ ${ }^{4}$ Stryker Trauma GmbH, Schönkirchen, Germany \\ ${ }^{5}$ Stryker Trauma AG, Selzach, Switzerland \\ ${ }^{6}$ Division for Applied Materials Sciences, The Ångström Laboratory, Uppsala University, Uppsala, Sweden \\ Email: ${ }^{\text {j.soerensen85@gmail.com }}$
}

Received 11 September 2014; revised 29 November 2014; accepted 8 December 2014

Academic Editor: Jinghua Duan, Department of Pharmaceutics, School of Pharmacy, University of Washington, USA

Copyright (C) 2015 by authors and Scientific Research Publishing Inc.

This work is licensed under the Creative Commons Attribution International License (CC BY).

http://creativecommons.org/licenses/by/4.0/

(c) (i) Open Access

\section{Abstract}

The early fixation of bone screws after surgical implantation still remains a challenge in the field of traumatology. Whilst hydroxyapatite (HA) coatings are known to enhance the fixation of implants; their removal at a later time-point may be problematic. An HA coating has been developed to demonstrate that both implant fixation and safe removal are feasible in the same design. Accordingly the aim of this study was to compare the in-vivo performance of thin biomimetic HA coated titanium screws to uncoated counterparts used as control after bilateral implantation in the femoral condyle of 36 New Zealand White Rabbits. The screws were analysed macroscopically, by histology, micro-CT and biomechanically at both two and six weeks post-implantation. The HA coated screws demonstrated excellent biocompatibility. At two weeks the HA coated screws demonstrated a significant increase in removal torque values as well as a strong trend towards higher pull-out forces. In addition histology confirmed a higher degree of osseointegration and direct bone to implant contact. At six weeks no difference in pull-out force and removal torque could be detected. SEM images confirmed the absence of any residual HA coating indicating a fast coating degradation in-vivo. The low level of removal torque after full osseointegration at 6 weeks supports the feasibility of safe and easy removal of the implant. The HA coating under study appears

\footnotetext{
${ }^{*}$ Corresponding author.
} 
to offer a unique characteristic of enhanced fixation with a minimal increase in removal torque after full osseointegration. This may be of value in clinical applications where it is necessary to assure both screw fixation and later removal.

\section{Keywords}

\section{Biomimetic Hydroxyapatite, In-Vivo, Screw, Implant Removal, Pull-Out Force, Removal Torque}

\section{Introduction}

As a sequel to the internal fixation of bony fractures implant loosening, migration and screw cut-out are major post-surgery complications that may require a second surgery to remediate [1] [2]. Orthopaedic bone screws are most frequently implanted devices and these are either used on their own or more commonly used in combination with plates or intramedullary implants. The clinical applications of this class of implants are broad and include fixation and stabilization of wide range of orthopaedic conditions. The early fixation of screws in bone is an essential characteristic and is influenced by implant design, implant fit, materials used for fixation as well as biological aspects like bone quality and area of implantation [3] [4]. Depending on the implantation site and the type of implant used, quite different rates of screw cut-out, migration and loosening are reported. For example in 3 and 4 part fractures of the proximal humerus plate and screw failure rates up to $40 \%$ are reported in older patients (>60 years age) [1] [5]. Whilst in fractures of the hip, treated with internal fixation, the reported hip-screw cut-out rates range from $6 \%$ to $19 \%$ [2]. For such clinical applications current implant solutions clearly do not meet all the clinical needs.

After implantation in-vivo in bone there is typically an early resorption phase close to the implant [6] [7] resulting from a foreign body reaction although long term stability is also reported. In an attempt to enhance implant fixation Hydroxyapatite (HA) coatings have commonly been employed. Such HA coatings are known to be both biocompatible and to enhance osseointegration of implants. This is due to their chemical and crystal resemblance to the mineral component of bone adjacent to the implant [8]. In general more rapid and enhanced fixation is reported which is the primary intention of such coatings [9]-[19]. HA and similar derivatives have been extensively studied [8], encompassing quite different morphologies, topographies and crystal structures that are very dependent on the manufacturing processes employed [20]-[22]. HA manufacturing methods include the sol-gel deposition, electrochemical techniques, biomimetic processes [23]-[25] and plasma spraying [9] [26]-[28]. As part of the manufacturing process it is usual to modify the surface of the implant by some form of surface treatment. What differentiates the thin $(\sim 1-2 \mu \mathrm{m})$ biomimetic HA coating under study was that it was designed to be deposited on an "as-manufactured" titanium implant with its protective Anodisation type II surface (no special surface roughening is required). The authors hypothesized that by using a commercial "as finished" titanium screw that, due to the relatively smooth surface finish, removal torques would be relatively low whilst at the same time there would be increased pull-out force. By such means it may be possible to enhance early screw fixation in bone by means of a biomimetic hydroxyapatite coating and at the same time ensure screw removal at a later time point without undue damage to either the bone or the implant.

A lapine animal model was used as it was thought to be sufficiently sensitive to demonstrate differences at two selected time points with respect to screw pull-out and screw removal torque. This was done at both two and six week time periods post implantation to represent early implant stabilization and subsequent full osseointegration.

The goal of the study was to determine if there would be improved implant fixation, at each time point, as measured by screw pull-out force: additionally that there would be a relatively modest screw removal torque indicating relatively low risk of damage to either the screw or the bone.

\section{Materials and Methods}

\subsection{Substrate Materials}

$\mathrm{Ti}_{6} \mathrm{Al}_{4} \mathrm{~V}$ Ti cancellous screws $(\varnothing 4.0 \mathrm{~mm} \times 14 \mathrm{~mm})$, obtained from Stryker AG (Selzach, Switzerland) were used as control samples. Thin HA coated (1 - $2 \mu \mathrm{m})$ cancellous bone screws (same type) served as test samples. 


\subsection{Coating Deposition}

Untreated Ti cancellous bone screws were first sonicated in acetone for 5 minutes, then sonicated in ethanol for 5 minutes, and finally sonicated for 5 minutes in deionized water. An alkaline pretreatment was performed by placing the screws in a $5 \mathrm{M} \mathrm{NaOH}$ solution for 10 minutes at $70^{\circ} \mathrm{C}$. Thereafter the screws were placed in 1 liter of phosphate buffered saline (Dulbecco's PBS, Sigma, Steinheim, Germany) for $72 \mathrm{~h}$ at $70^{\circ} \mathrm{C}$. A holder was devised that prevented coating of the screw heads and allowed for all screws to be simultaneously coated. Stirring of the PBS with a magnet stir bar was adjusted to minimize the formation of HA aggregates on the HA coating. After removal from the PBS solution, the screws were removed from the holder, rinsed in deionized water and dried in nitrogen atmosphere. HA coated Ti screws were denoted as Ti-HA followed by a characteristic suffix.

\subsection{Animal Model}

All animal work was approved by both an internal and an independent external ethical committee and performed according to the ethical guidelines of NAMSA Lyon, Chasse sur Rhône, France.

\subsubsection{HA Performance Main Study Design}

Thirty-two aged ( $>24$ weeks) rabbits plus four reserve rabbits were randomly implanted with one test or one control article in each medial femoral condyle. At either two or six weeks after implantation, the rabbits were euthanized. The local tissue effects and bone healing performance were evaluated by macroscopic, radiographic, histopathology and micro-computer tomography analyses. The biomechanical properties of the bone/screw interface were evaluated with removal torque measurements. Alternatively, a pull-out test was performed at both time points. All investigations performed are summarized in Table 1.

The reserve rabbits were operated on using the same surgical procedure as the other rabbits. They were followed in exactly the same manner up to the end of the study and were planned to potentially replace rabbits removed from the study in case of unforeseen rabbit loss or any adverse event. At the end of the study, no abnormal event had occurred requiring the inclusion of these rabbits. Therefore, all reserve animal sites were sampled (control and test) and used for biomechanical testing.

\subsubsection{Surgical Procedure and Termination}

The surgical procedure was performed by an experienced veterinary surgeon using standard aseptic techniques. A skin incision was made on the medial side of the femur at the level of the epiphysis. The muscles were separated using blunt dissection to access the medial condyle and the periosteum was removed from the condyle surface. The entry point for drilling was localized between the distal part of the growth plate and the insertion of the collateral-lateral ligament. The direction of drilling was perpendicular to the bone surface. Bone defects were made using a cordless power tool. Drilling was initiated by introducing a $1.4 \mathrm{~mm}$ diameter guide wire to the depth of the opposite cortex. To avoid perforation of the lateral cortex, the guide wire was laser marked to indicate $10 \mathrm{~mm}$ insertion depth. A $2.7 \mathrm{~mm}$ diameter cannulated drill was then inserted with a stop at $10 \mathrm{~mm}$ depth. Continuous irrigation was applied to limit the thermal impact of drilling. After removal of the drill, the defect was extensively rinsed with saline to remove bone debris. The guide wire was removed together with the drill and the guide wire was not replaced and the tapping procedure was conducted without the guide wire. The drill

Table 1. HA-performance main study design.

\begin{tabular}{|c|c|c|c|c|c|}
\hline & \multirow{2}{*}{$\begin{array}{c}\text { Time-period } \\
\text { Group }\end{array}$} & \multicolumn{2}{|c|}{2 weeks } & \multicolumn{2}{|c|}{6 weeks } \\
\hline & & Test group & Control group & Test group & Control group \\
\hline \multirow{5}{*}{ 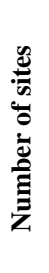 } & Histopathology analysis \& micro-CT & 4 & 4 & 4 & 4 \\
\hline & Pull-out test & 6 & 6 & 6 & 6 \\
\hline & Removal torque measurement & 6 & 6 & 6 & 6 \\
\hline & Reserve sites & 2 & 2 & 2 & 2 \\
\hline & Total & 18 & 18 & 18 & 18 \\
\hline
\end{tabular}


hole was tapped using a $4 \mathrm{~mm}$ diameter screw tap. The guide wire was removed and the defect was rinsed again with saline to remove bone debris. The spacing device was used to create a standardized distance between bone surface and screw head. The screw was inserted until it was in contact with the spacer and was then unscrewed $1 / 4$ turn to release the spacer. The standardized gap between screw head and bone was necessary to ensure that there was access for the pull-out test jig and additionally to prevent bone overgrowth covering the screw head. These steps were taken to minimize biological variance impact on the pull-out and removal torque measurements. The contralateral femur was similarly treated. The incisions were then closed by suturing the muscle and cutaneous layers separately with absorbable suture (Vicryl or PDS ${ }^{\mathrm{TM}}$ II, Ethicon). Medio-lateral and antero-posterior radiographs were taken to locate each screw (angle and insertion depth). Two and six weeks after implantation, the rabbits were sacrificed by an intravenous injection of pentobarbital (Dolethal ${ }^{\circledR}$, Vetoquinol) preparation.

\subsection{Biomechanical Studies}

\subsubsection{Pull-Out Force Measurements}

The evaluation offixation strength by a pull-out test for each screw implanted in each distal femoral metaphysis was enabled by the preset $2.5 \mathrm{~mm}$ distance between the screw head and the bone surface allowing for the use of a special pull-out tool. The femurs were shortened and embedded in PMMA in containers as described above for the removal torque measurement. The containers were removed from the embedding tool and then each was placed in a materials testing machine (Z10, Zwick, Einsingen, Germany) in a special fixture, cf. Figure 1. The container holding the specimen and screw was positioned under a perforated plate to enable access of the special pull-out tool. The pull-out tool was fixed to a load cell (U1, $10 \mathrm{KN}$, Hottinger Baldwin Measurements).

The crosshead of the material testing machine was moved upwards at a constant displacement rate of 5 $\mathrm{mm} /$ minute force and displacement were continuously registered until a clear drop in the pull-out force was observed.

\subsubsection{Removal Torque Measurements}

A removal torque test was carried out to evaluate the torsional fixation of the screws. For this purpose a custom-made torsion apparatus was used. After explantation the femurs were shortened to 15 - $20 \mathrm{~mm}$ length, including the distal end, and were then embedded in polymethylmethacrylate (PMMA) (Technovit 3040, Heraeus Kutzer, Wehrheim, Germany). To achieve an exact alignment of the screw with the removal tool (standard surgical hex key) a special embedding tool was designed allowing for simultaneous embedding of 8 femurs, cf. Figure 2(a). During curing of the polymethacrylate the containers were cooled with ice to quickly dissipate the heat.

Subsequently the containers were mounted in the custom made test assembly, cf. Figure 2(b), which was placed in a standard materials testing machine (Z10, Zwick, Einsingen, Germany) equipped with a $50 \mathrm{~N}$ load cell (KAP-TC, A.S.T./Z wick, Einsingen). The testing device allowed creating an unscrewing torsion moment. The removal tool (hex key) was placed in the hexagon socket of the screw with a longitudinal clearance of 0.5 $\mathrm{mm}$ so that the screw was able to move longitudinally while applying the removal torque. The crosshead of the material testing machine was moved downwards at a constant displacement rate of $3.06 \mathrm{~mm} /$ minute resulting in a torsion rate of $5 \%$ minute. The torsion angle was calculated with the registered displacement of the loading punch $\mathrm{u}$ and the lever arm $l(35 \mathrm{~mm})$ according to

$$
\alpha=\arctan \frac{u}{l}
$$

The effective torsion moment was the product of the registered force $\mathrm{F}_{\text {reg }}$, and the lever arm $l(35 \mathrm{~mm})$.

\subsection{Scanning Electron Microscopy (SEM) Characterization}

Selected coated and uncoated Ti bone screws were imaged with SEM (XL30 ESEM, FEI, Netherlands) using the secondary electron detector.

\subsection{Histological Preparation}

After complete fixation, implantation sites were dehydrated in alcohol solutions of increasing concentrations, 


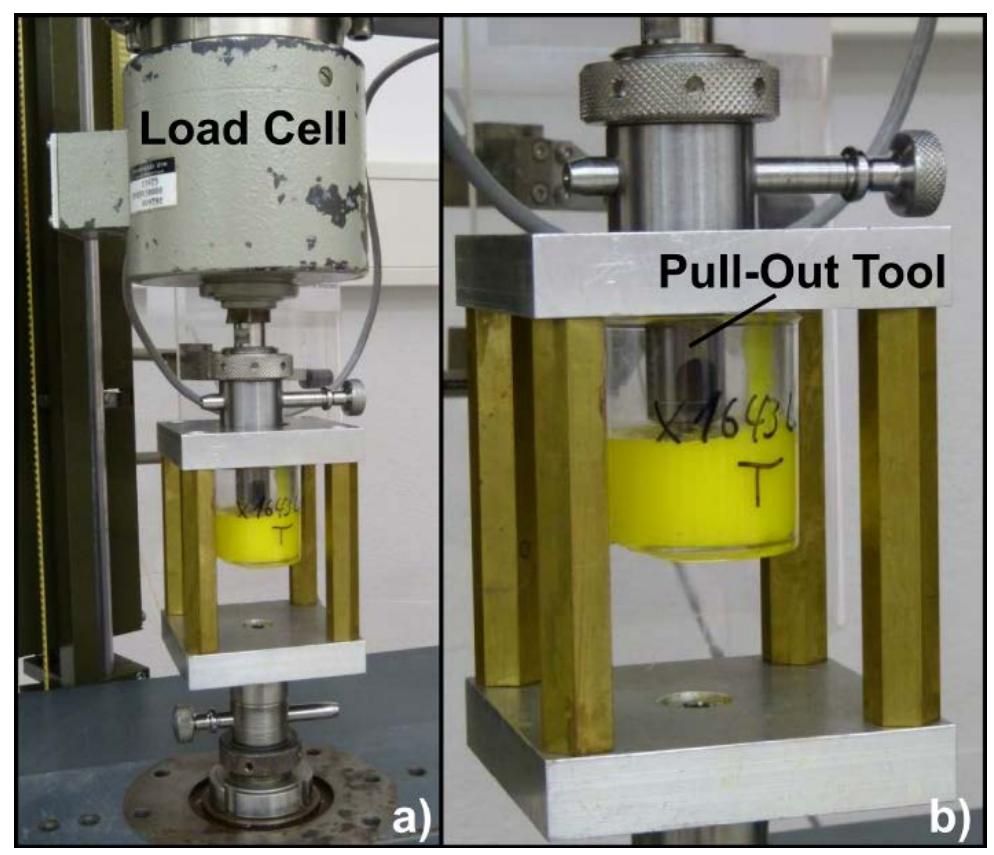

Figure 1. Test assembly for the pull-out test. a) Overview of the test set-up with load cell and b) container placed under the perforated plate with pull-out tool (magnification of a)).

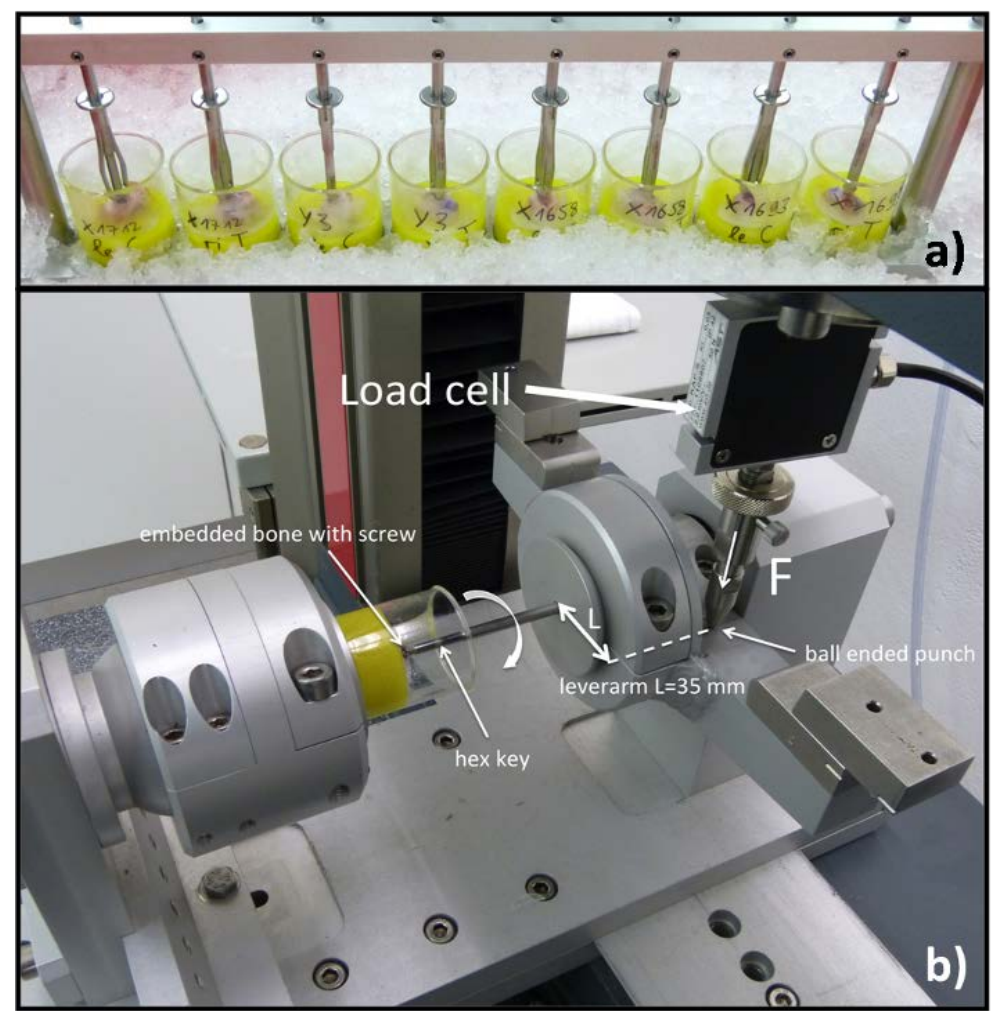

Figure 2. a) Custom made embedding device. standard surgical hex keys with screw holding clamp reaching perpendicularly into the embedding containers; b) test assembly placed in the material testing machine showing the removal torque tool tool (hex key) pointing into the screw. The ball ended punch creates an unscrewing torsion moment $(\mathrm{F} * \mathrm{~L})$. 
cleared in xylene and embedded in PMMA resin. After micro-CT analysis, one longitudinal central cross section of each site was obtained by a micro-cutting (thickness of each section between 20 to $30 \mu \mathrm{m}$ ) and grinding technique. Sections were stained with modified Paragon for qualitative, semi-quantitative and quantitative analysis.

\subsubsection{Histomorphometric Preparation}

Quantitative histomorphometric analyses were conducted by scanning and examining slides with a Zeiss Axioscope microscope equipped with a color images analyzing system (Samba, version 4.27, Samba Technologies, France). The regions of interest (ROI 1 and 2) were investigated as defined in Figure 3.

Quantitative analyses were further performed to assess the percentages of the contact and area density parameters within the ROIs 1 and 2. The contact parameters describe the bone to implant contact as well as the soft tissue contact and the bone marrow contact. The area density was divided into bone area density (percentage of the ROI occupied by bone tissue in terms of surface area), as well as soft tissue area, bone marrow area and implant area density. The quantitative results of ROI 1 and ROI 2 were summed for analysis and the resulting average values were evaluated.

\subsection{Micro-CT}

\subsubsection{Micro-CT Measurements after Removal Torque Testing}

Prior to micro-CT scanning 14 screws were removed from the femurs ( 7 control and 7 test articles after 6 weeks in-vivo). The bones were placed with their embedding containers (including the PMMA) in a micro-CT (SkyScan 1172, Bruker-Mikroct, Kontich, Belgium) and scanned at a resolution of $30 \mu \mathrm{m}$. Subsequently, the cortical thickness was measured at 4 points ( 2 in 2 perpendicular planes) using an evaluation tool provided by the CT manufacturer (Skyscan) and averaged, cf. Figure 4.

\subsubsection{Micro-CT Measurements}

After fixation and resin inclusion and before histological evaluation, the sites were analyzed via micro-CT (Bruettisellen, Switzerland). The samples were scanned by micro-computed tomography (CT 100, Scanco Medical AG, Switzerland) using an energy of $90 \mathrm{kVp}$ at an intensity of $88 \mu \mathrm{A}$. The integration time was adjusted to $600 \mathrm{~ms}$ at a double fold frame average. Nominal isotropic resolution was set to $11.4 \mathrm{~m}$. To segment bone around the implant, measured data was filtered using a three-dimensional constrained Gaussian filter with finite filter support $(1$ voxel) and filter width (sigma $=0.5$ ). The outer border of the volume of interest (total volume $=\mathrm{TV}$ ) for the bone region around the implant was defined by apredefined distance of $0.5 \mathrm{~mm}$. from the implant thread surface cf. Figure 5.

Bone and implant were segmented as separate phases. As the interface of the implant to bone was blurred due to the partial volume effect, morphologic operators were used to identify the bone to implant contact area. The bone implant contact (BIC) was then analyzed slice by slice. As part of the implant head of the screw was outside the bone, the analysis region was limited to a height of 860 voxels starting 2 voxels above the tip of the implant.

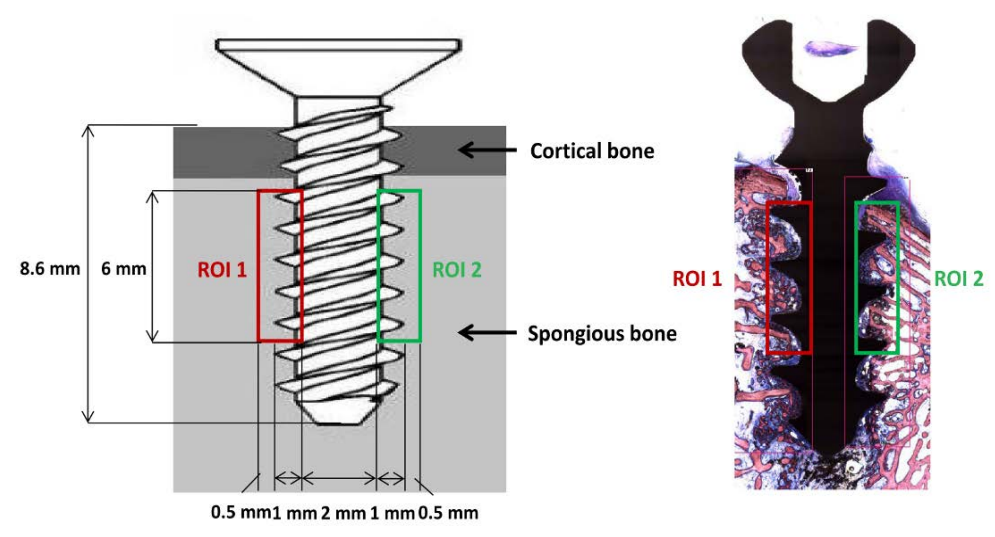

Figure 3. Schematic drawing (left) and pictorial overview (right) of the regions of interest investigated for the histomorphometric analysis. 


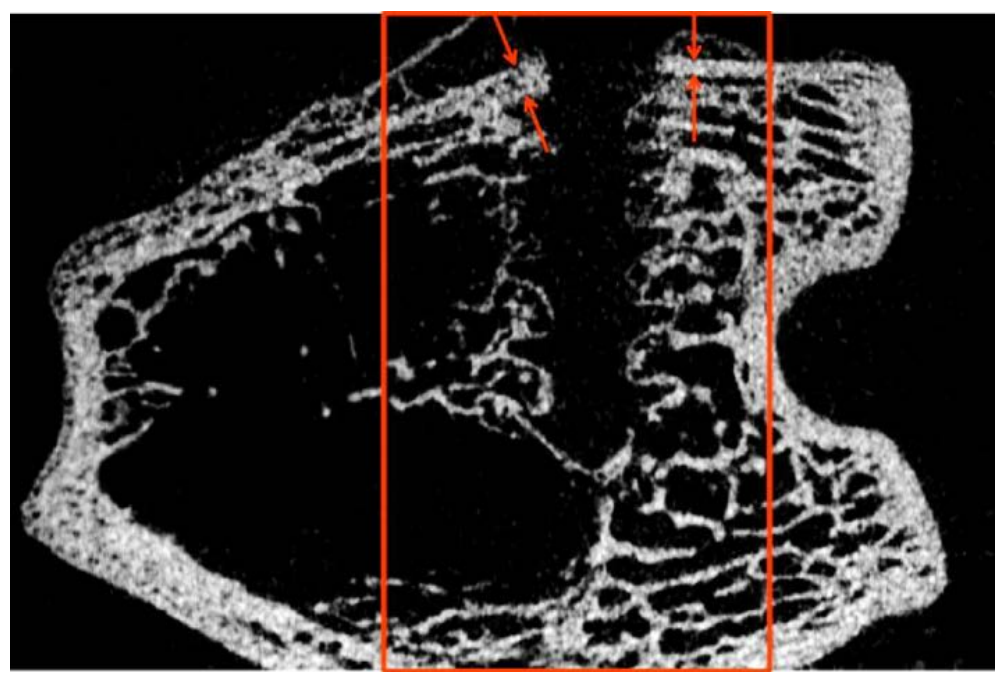

Figure 4. Micro-CT image of the bone after screw removal. The arrows indicate the cortical thickness measurement (here in one plane).

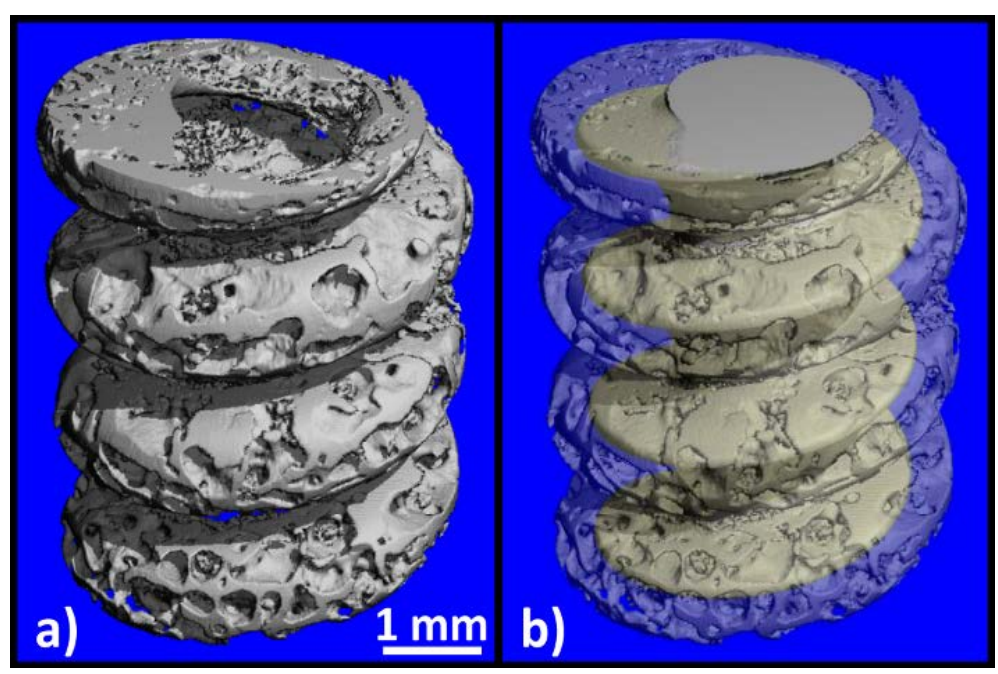

Figure 5. The defined region of interest (ROI) can be observed in the left image a)); the right image b)) demonstrates the screw (grey part) and the ROI described by the transparent part.

\subsection{Statistical Evaluation}

After summarizing the valid data points, all relevant descriptive parameters were identified to assess the mean and variance of the data. Normality of all continuous variables was assessed with the Shapiro-Wilk Test [29]. Due to the small sample sizes in each group the prediction of a normal distribution is imprecise, regardless of the Shapiro-Wilk Test outcome. Therefore, the unpaired Mann-Whitney Test was selected for comparison. Additionally, Monte Carlo Simulation was used to raise the precision of test outcome. The level of significance for all tests was set to $95 \%$ ( $\mathrm{p}<0.05$ was significant). All calculations were performed with the software PASW Statistics Version 18.0.2 (SPSS). For graphical visualization and comparison box- and whisker plots were chosen for all variables (control and test) and time points (two or six weeks). Values deviating more than 1.5 times the interquartile range distance were considered as outliers and marked as circles. Values shown in the graphs of $\mathrm{p}<0.05$ were considered significant and values of $\mathrm{p}<0.01$ highly significant. Statistically significant differences between the implant types (control and test) and time points (two and six weeks) are labeled in the diagram by a line and the corresponding p-value. 


\section{Results}

\subsection{Pull-Out Measurements}

The median of the maximum pull-out forces at two and six weeks post implantation are described in Figure 6. No statistically significant differences in pull-out force were demonstrated comparing uncoated control and the HA coated test articles at both two and six weeks. A clear trend of higher pull-out forces was, however, observed for the HA coated test article at two weeks. Bilateral comparison of all 6 pairs of femurs demonstrated higher pull-out forces for every single test item compared to its respective control counterpart. This trend would become statistically significant if the group size was increased to $n=12$ instead of $n=6$ (power analysis with 1 $\beta=0.80$ ). The internal comparison of the test and control groups between two weeks to six weeks implantation demonstrated a significant increase in pull-out forces for the control $(\mathrm{p}=0.008)$ and for the test group $(\mathrm{p}=$ $0.001)$.

\subsection{Removal Torque Measurements}

Maximum removal torque values of both control and test articles at two and six weeks after implantation are summarized in Figure 7. After two weeks a significant increase $(p=0.012)$ in removal torque was measured for HA coated test articles compared to control articles $(p=0.012)$. The median of the maximum moment of 3.1 $\mathrm{Ncm}($ mean $=2.7 \mathrm{Ncm}$ ) measured for the control group after two weeks significantly increased for the test group resulting in a median value of $8.2 \mathrm{Ncm}$ (mean $=7.6 \mathrm{Ncm}$ ). After six weeks no significant difference in maximum removal torque values were detected comparing control and test articles. The median/mean values demonstrate a trend towards slightly increased removal torque values for the test article (median $=13.4 \mathrm{Ncm}$; mean = $12.8 \mathrm{Ncm}$ ) compared to the control articles (median = $11.9 \mathrm{Ncm}$; mean = $10.9 \mathrm{Ncm}$ ) after six weeks. However, when comparing control versus control group and test articles versus test articles at two and six weeks post-implantation a significant increase in removal torque was detected for both groups internally. This difference was highly significant for the control groups between two to six weeks.

\subsection{SEM Evaluation after Screw Removal}

The SEM images shown in Figure 8 are from both HA coated and control bone screws post removal. Test and control screws were removed using the torque measurement system after two and six weeks in-vivo and then analyzed.

In general, at two weeks a residue of the HA coating was found on the screw portion that was inserted into the bone. HA was visible below the screw head and down to just above the first thread and some proportion was

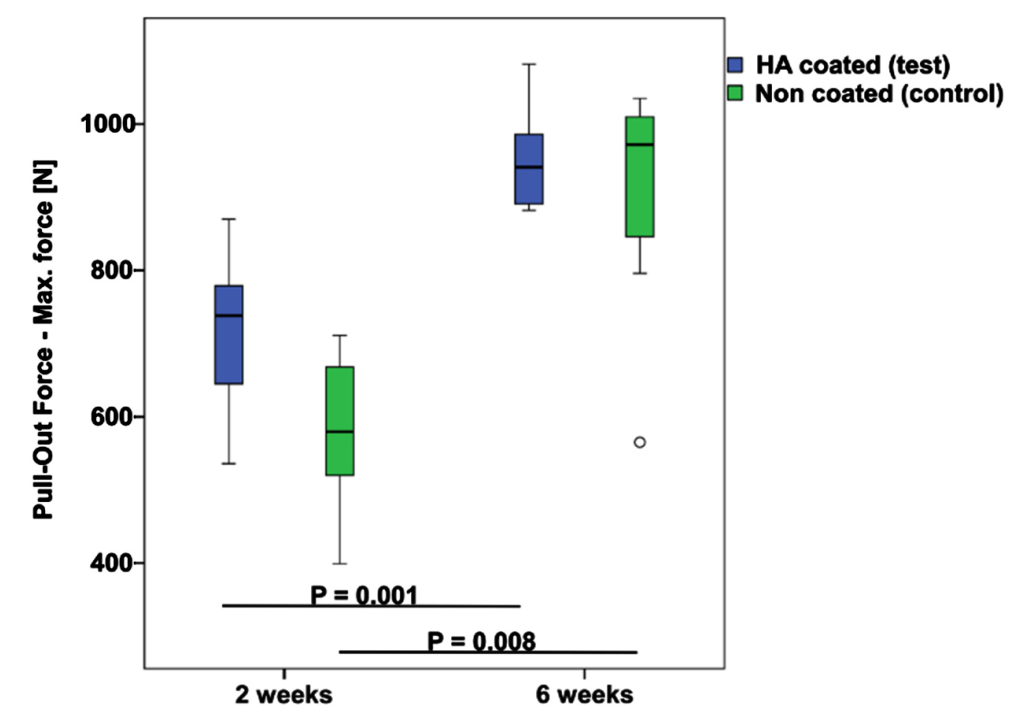

Figure 6. Maximum pull-out force after 2 and 6 weeks implantation of test (n $=6$ each time point $)$ and control articles ( $\mathrm{n}=6$ each time point). 


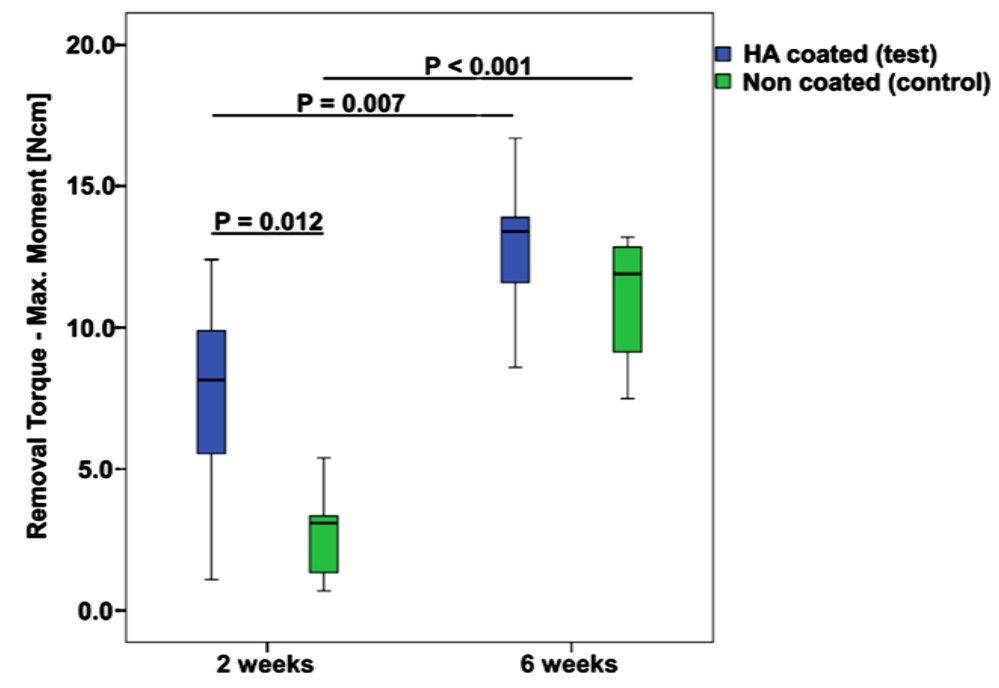

Figure 7. Maximum removal torques after 2 and 6 weeks implantation of test ( $n=6$ each time point) and control articles ( $n=6$ each time point).

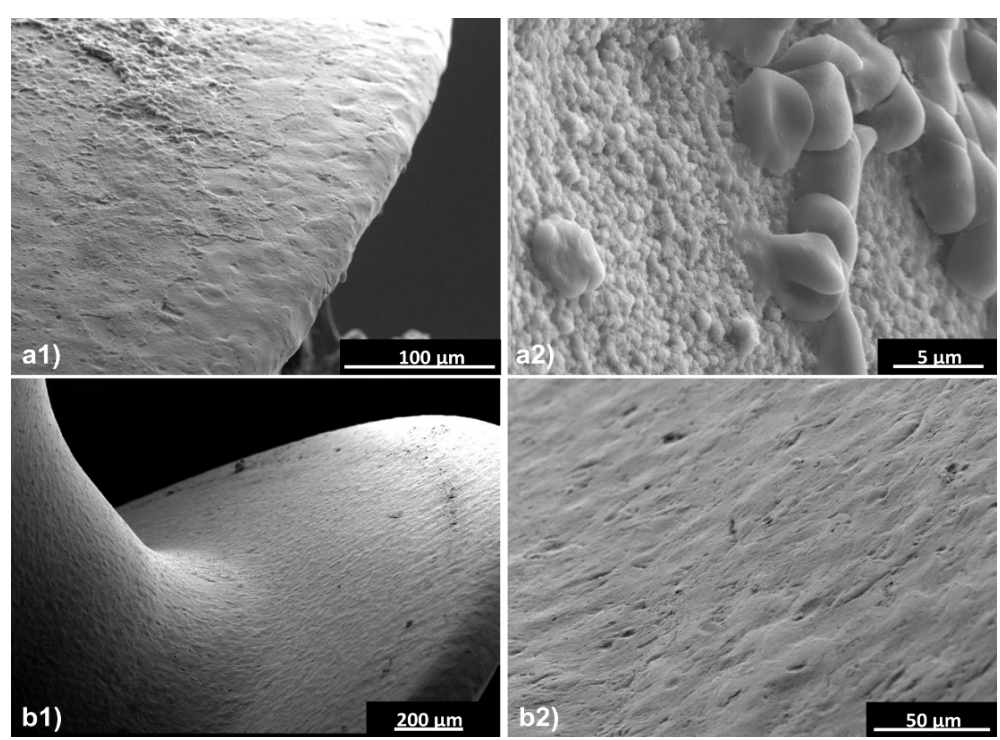

Figure 8. SEM images after screw removal of a test screw 2 weeks (a1 and a2) and 6 weeks (b1 and b2) of implantation-a1) and b1) display the surface between the threads. Residual HA and cell attachment can be observed after 2 weeks (a1 and a2), whereas no residual HA can be observed for the test groups after 6 weeks in-vivo (b1 and b2).

covered with HA growth, cf. Figure 8. The control screw demonstrated signs of cell attachment at the screw tip and between the threads after two weeks in-vivo.

The HA coated test screws displayed clean areas without residual HA coating as well as spots clearly demonstrating residual HA at the screw interface. Cell attachment was observed within these areas.

At six weeks in-vivo the control screws showed areas of cell attachment directly at the titanium surface. The test articles did not show any evidence of residual HA at six weeks implantation in-vivo and only minor cell attachment, cf. Figure 8.

\subsection{Histological Evaluation}

A total of 8 sections ( 4 control sites and 4 test sites) were analyzed for each time point. At two weeks implanta- 
tion, the histopathologic analysis showed no local adverse effects in the control and test groups. Qualitatively a higher level of osseointegration was observed with the test article, cf. Figure 9. This was not confirmed statistically through the histomorphometric analysis, even though a higher value of bone to implant contact was determined in the test group. However, the soft tissue contact developed with control screws was significantly higher than with the test screws.

At six weeks, the bone tissue matured in the two groups. Although a slightly higher amount of bone tissue was qualitatively observed with the test group, quantitatively no significant difference was seen between the test and control groups, cf. Figure 10.

In general at six weeks there was evidence of thickening of the bone trabeculae together with moderate signs of bone remodeling around the control and the test screws. A moderate grade of cancellous bone was seen to grow towards the surfaces of both the control and the test sites. The signs of osseointegration and osteoconduction slightly increased compared to two weeks for both groups. The osseointegrated bone debris (surgery-related) was remodeled after this time period. A significant increase of bone density in the test group was noted between two and six weeks, while bone density remained stable in the control group.

In conclusion, the HA coated test screw slightly outperformed the control article in terms of qualitative periimplant bone healing, however, with the limitations of the study this difference did not achieve statistical significance.

\subsection{Micro-CT Evaluation after Removal Torque Measurements}

The main finding during the micro-CT evaluation after removal torque testing was that the cortices were much thinner than the $1.5 \mathrm{~mm}$. This was the threshold value above which Seebeck et al. [30] asserted that the pull-out force of a screw is mainly influenced by the cortical bone thickness rather than the quality of the underlying cancellous bone. This suggests that the pullout force measured in the present study is likely to represent the strength of the connection of the screw to the underlying cancellous bone. The mean values of cortical thickness of femurs treated with control $(0.62 \mathrm{~mm})$ and test articles $(0.57 \mathrm{~mm})$ were comparable.

\subsection{Micro-CT Evaluation}

The micro-CT for the ROI close to the interface showed no statistically detectable difference in bone volume
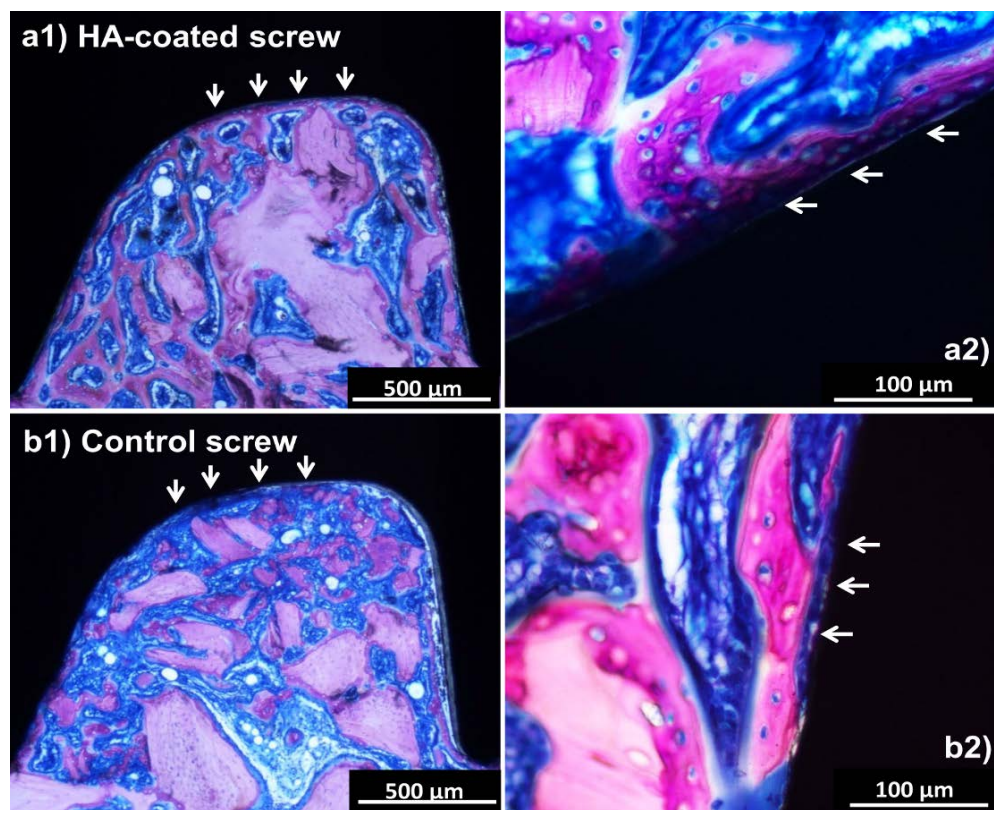

Figure 9. Histological images of HA coated screws (a1 and a2) and noncoated control screws (b1 and b2) after 2 weeks in-vivo. The arrows highlight direct bone implant contact (a1 and a2), whereas minor direct bone implant contact was observed for the control group (b1 and b2). 
density (BV/TV) between test and control at two and six weeks. However, at six weeks a slight trend towards higher bone volume density was observable for the test articles, cf. Figure 11. Furthermore, it was found, that trabecular elements were thicker and further separated at six weeks. Overall, no significant difference was found after evaluating a small number of specimens.

\section{Discussion}

The present in-vivo HA performance study generated a number of findings. Whilst there was no detectable impact of the HA coating during surgical implantation, there were substantial differences in in-vivo behavior as demonstrated by the biomechanical and histological analyses. The measured removal torque significantly in-
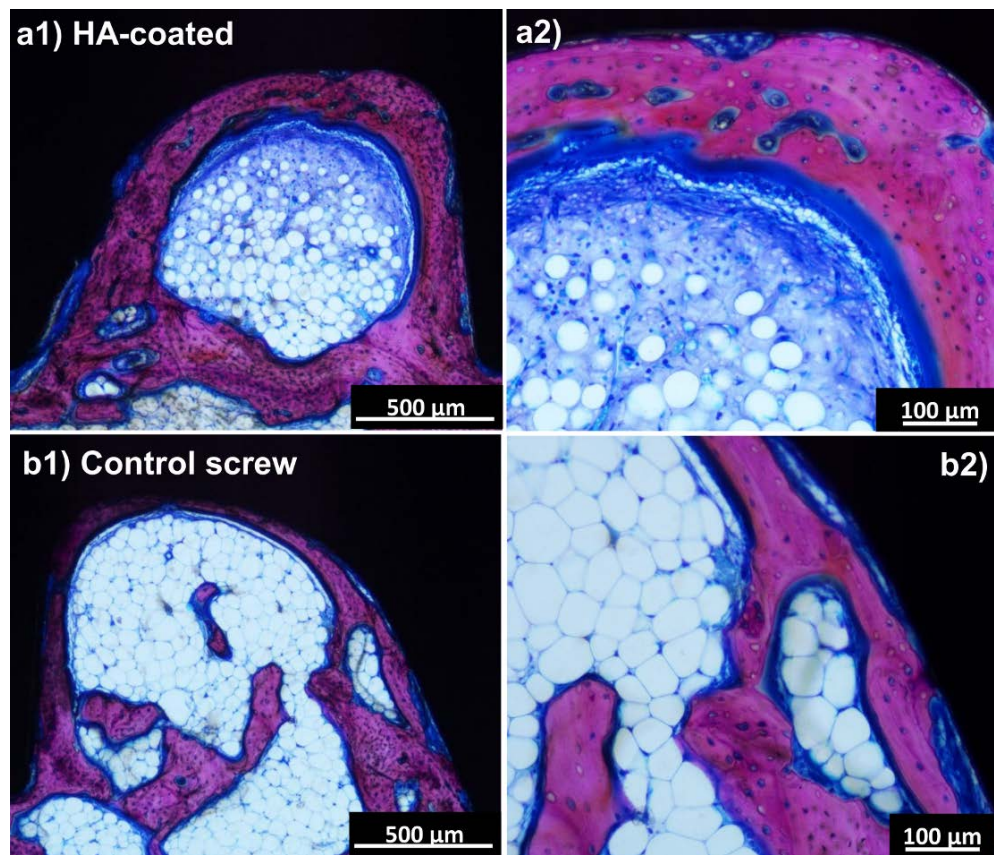

Figure 10. Histological images of HA coated screws (a1 and a2) and noncoated control screws (b1 and b2) after 6 weeks in-vivo. For both samples tested a good osteocoductivity was demonstrated. A greater bone thickening and a higher remodeling activity was observed for the HA-coated group.

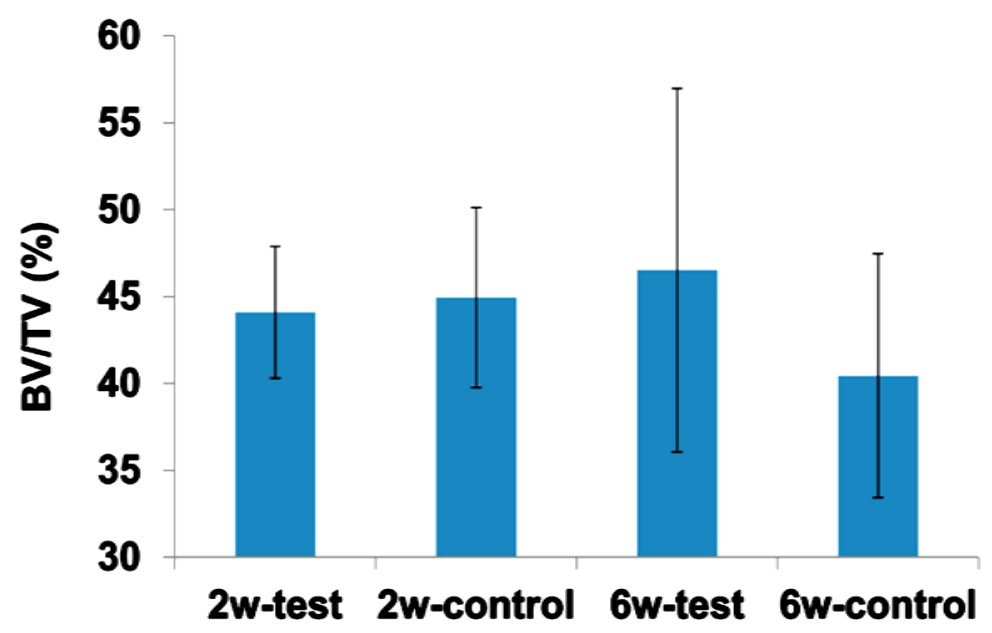

Figure 11. Bone volume/Total volume BV/TV (\%) demonstrated for the test and control articles at 2 and 6 weeks in-vivo. 
creased for the HA coated test screws after two weeks compared to control screws. The same trend was seen in the pull-out forces measured at two weeks. These results, supported by histological results, demonstrate more rapid implant stabilization has been effected by the thin biomimetic HA coating. At six weeks no trends or statistical differences could be found within the biomechanical analyses. Whilst there was an increase in removal torque at 6 weeks the values measured were almost an order of magnitude below the torques that would damage the screwdriver or the screw itself. Therefore the removal of the screws was safe and straight forward even after full osseointegration had occurred. SEM analysis of the screw surface after removal torque measurements demonstrated signs of residual HA after two weeks, but no residual HA coating at six weeks, which confirms remodeling occurred during this time period. A positive effect of the coating was seen in the histological analyses where the HA coated screws induced a greater bone thickening and increased bone to implant contact.

It is reported that in the literature that HA is able to increase the osseointegrative ability of screws and fixation pins and results in increased fixation strength of up to 2.5 times that of non-coated implants as measured by removal torque [31] [32]. After two weeks in-vivo this is fully in line with the findings of this study, showing a removal torque increase of up to 2.8 times. Plasma-sprayed HA coatings on implant surfaces in particular have already demonstrated high clinical success rates in external fixation pin applications. This is as a result of greater bone-pin contact, enhanced bone-integration and proven long term fixation [33]-[35]. They are designed to permanently connect the implant to the bone. These aims are particularly desirable in the field of total jointreplacement. Plasma sprayed HA coatings have also found their application in the area of external fixation [31], where fast stabilization of the external pins is necessary. In the field of traumatology the removal of implants often is necessary and desirable e.g. in the case of a revision surgery. Therefore the biomimetic HA coating under study appears to have the potential for safe removal after full osseointegration. The short and longer term effects of the HA coating were evaluated at two and six week time points after implantation after careful consideration. Two weeks after implantation was chosen as an early time point because several studies in rabbit bones demonstrated significant histological and biomechanical differences after two weeks in-vivo. Slaets et al. [7] reported of the presence of basic remodeling units in the surrounding bone, reaching a maximum after 7 days of implantation. Yang et al. [36] [37] studied the removal torques of implants at 2, 4 and 8 weeks in rabbits. He reported a measureable difference in removal torques after these time points. With this as background two weeks post implantation was selected as the early time point of choice to assess early biological and biomechanical changes associated with the thin-HA coating. In the present study early implant stabilization was demonstrated by the thin HA coating. Zhang and Zou [38] reported better surface bioactivity and osteoconductivity of HA coatings, which could lead to the higher biomechanical forces needed for removal and pull-out of the screw seen for the test articles under study. Eom et al. [39] confirmed that HA coatings are favorable in early loading stages. "Biologically, the early phase (days) after implantation of an implantable device is considered to be critical to the long-term implant stability" [40]. The HA coating appears to improve early implant stabilization and therefore, ensures that initial implant placement is maintained [41] [42]. After implantation the HA coating was modulating the early biological response of the bone and the surrounding tissue to the screw implant. In this situation the bone was not in direct contact with the metal implant, the contact interface consists of bone-like HA in contact with bone. Consequently, the body may not immediately react to the screw as it would for metallic foreign matter. Faster and better cell attachment is likely the result with more rapid vascularization and calcification. It is also speculated, that human cells prefer the osteoconductive surface exposed by the HA to win the "race of the surface" against bacteria infiltrating during surgery. After the rapid cell attachment phase, the thin coating is then remodelled by osteoclasts and osteoblasts. This appears reasonable during the initial weeks post implantation and is due to the high crystallinity and small coating thickness of the HA.

The six week time period was selected as an appropriate time point to look at the histological and biomechanical behavior after full osseointegration of the implant. Slaets et al. [7] reported that the length of the bone remodelling cycle is 6 weeks in the rabbit compared with about 4 months in humans. Sennerby et al. [43] support this view noting that bone around the implant was mature after 6 weeks as indicated by histology and biomechanical testing. Bone formation around-and adjacent to-the screw implant thread at this time point was also clearly observed by Rhoshan-Ghias et al. [44].

After HA remodelling and full osseointegration, the implant provided a good in growth and attachment to the bone, which was seen from histology. The values measured at six weeks for removal torques and pull-out forces comparing test samples and control articles resulted in no statistically observable difference in contrast to what was demonstrated at two weeks. This may be explained by the remodelling of the HA coating in-vivo. During 
SEM evaluation of the surface after screw removal only minor residual HA coating could be found on the HA coated screws after two and practically none at six weeks. The wear off or delamination of the HA coating during insertion can be excluded as there was evidence of significant differences in behaviour between HA coated and non-coated screws. Therefore, it could be postulated that the thin HA coating remodelled very rapidly in-vivo and that the absence of the coating at six weeks enabled easy and safe removal of the HA coated screws. Another potential explanation for the absence of coating could be that it disconnected during screw removal from the bone. This would be supported by the fact that only minor areas of HA coating could be seen even at two weeks in-vivo. The microstructure of the titanium surface underlying the HA-coating was not changed by the $\mathrm{NaOH}$ pretreatment prior to the coating process, as confirmed by inspection with SEM (not shown). Thus, the implant surface showed the same removal characteristics as seen for the non-coated reference implant after HA remodelling and the screw was removed without damage to the bone or to the surrounding tissue. The implant did not show increased pull-out forces as observed for plasma-sprayed HA coatings, which have very slow degradation rates [45]. Additionally, no signs of immune or inflammatory response could be found for the HA coating under study which is consistent with the results presented by Rigo et al. [46]. The results obtained in the current study demonstrated biomechanical resistance of the HA coating during insertion in-vivo. This has also been shown with the same type of biomimetic HA coatings in-vitro on external fixation pins by using different synthetic bone qualities [47] [48]. Nevertheless in-vivo proof was lacking in these studies. It could only be speculated if and how much coating wear was seen during insertion in-vivo but, clearly, effects of the coating could be demonstrated, supporting the hypothesis of minimal coating wear effects during insertion in-vivo. The in-vitro insertion tests reported were performed in a dry environment. During in-vivo insertion the fluids like blood, saline and fatty substances could behave like lubricants and thus reduce friction-induced coating wear effects [49].

To summarize, the two weeks histological evaluation, pullout and torsion tests showed effects and suggest that the coating had a measureable influence. In contrast the micro-CT showed no significant detectable difference for the defined ROI. Therefore the HA coating seems to have an early, very local, effect and there are some signs, although non-significant, that this early effect directly at-or close to- the implant interface is seen at the later time point in the form of increased bone formation. The HA coating does not act like an active pharmaceutical ingredient diffusing from the implant and additionally affecting the biological structures in the vicinity of the implant. A distance effect from the implant was reported earlier both by Peter et al. and Wermelin et al. [50] [51] describing increased bone density caused by zoledronic acid eluting coatings. In these studies the active pharmaceutical ingredient was shown to have a significant effect on bone remodeling for a distance of up to 400 $\mu \mathrm{m}$. This remodeling effect could not be detected after two weeks in the HA coating under study and confirms that the effect of HA on its own is more a surface-or close to surface-phenomenon.

Micro-CT measurements performed after removal torque evaluation gave information on the cortical thickness of the bones. The cortices were measured to be far below $1.5 \mathrm{~mm}$. Seebeck et al. [30] reported that $1.5 \mathrm{~mm}$ is the threshold above which the pull-out force is mainly influenced by the cortical rather the cancellous bone in a limited human cadaver bone series. In the present study the mean cortical thicknesses for test and control are far below this threshold suggesting that the pull-out force measured is mostly generated by the underlying cancellous bone. The differences in pull-out forces could therefore be attributed to the surface properties of the HA coated screws vs. non-coated screws. The micro-CT measurements additionally demonstrated good implant integration in cancellous bone.

\section{Conclusion}

The in-vivo performance of the HA coating on titanium screws confirmed stabilization of the implant which was still safely removable even after osseointegration. Significantly higher removal torques and a trend towards higher pull-out forces were measured for the HA coated implant compared to the non-coated implant after two weeks in-vivo. This supported the hypothesis of more early and more rapid stabilization in the presence of the HA coating. Nevertheless, after full osseointegration of the screw implants, the biomechanical tests demonstrated safe and relatively easy implant removal, which is an absolutely essential requirement for such implants if they fail or require revision surgery. SEM images confirmed disconnection of the HA coating and/or HA remodeling in-vivo. Histology confirmed that the HA coating was not visible at both time points and had been replaced with newly formed bone that was intimate with the implant surface, whereas controls showed greater 
fibrous tissue at the implant surface. This unique "disconnection” characteristic has never been demonstrated before. Metallic implants with bioactive HA coatings are expected to enable the implant to bear load at earlier time points. This was confirmed in the present study by the significantly higher biomechanical removal torques for the HA coated screws after osseointegration in-vivo. Thus the HA coating design goal of enablingmore rapid fixation post-surgery whilst being still safely removable after full osseointegration was achieved. Additionally the structure of the coating provides the ability to load it with active pharmaceutical ingredients and further focus on anti-infective and/or anti-osteoporotic topics.

\section{Acknowledgements}

The European Commission as part of the $7^{\text {th }}$ Framework programme-BIODESIGN as well as the Swedish Science Council is gratefully acknowledged for financial support. Claudia Beimel is acknowledged for performing the statistical analysis. NAMSA is acknowledged for performing the animal study.

\section{References}

[1] Krappinger, D., Bizzotto, N., Riedmann, S., Kammerlander, C., Hengg, C. and Kralinger, F.S. (2011) Predicting Failure after Surgical Fixation of Proximal Humerus Fractures. Injury, 42, 1283-1288. http://dx.doi.org/10.1016/j.injury.2011.01.017

[2] Adams, C.I., Robinson, C.M., Court-Brown, C.M. and McQueen, M.M. (2001) Prospective Randomized Controlled Trial of an Intramedullary Nail versus Dynamic Screw and Plate for Intertrochanteric Fractures of the Femur. Journal of Orthopaedic Trauma, 15, 394-400. http://dx.doi.org/10.1097/00005131-200108000-00003

[3] Basler, S.E., Traxler, J., Müller, R. and van Lenthe, G.H. (2013) Peri-Implant Bone Microstructure Determines Dynamic Implant Cut-Out. Medical Engineering \& Physics, 35, 1442-1449. http://dx.doi.org/10.1016/j.medengphy.2013.03.016

[4] Windolf, M., Braunstein, V., Dutoit, C. and Schwieger, K. (2009) Is a Helical Shaped Implant a Superior Alternative to the Dynamic Hip Screw for Unstable Femoral Neck Fractures? A Biomechanical Investigation. Clinical Biomechanics, 24, 59-64. http://dx.doi.org/10.1016/j.clinbiomech.2008.07.004

[5] Fakler, J.K.M., Hogan, C., Heyde, C.E. and John, T. (2008) Current Concepts in the Treatment of Proximal Humeral Fractures. Orthopedics, 31, 42-51. http://dx.doi.org/10.3928/01477447-20080101-13

[6] Dhert, W.J., Thomsen, P., Blomgren, A.K., Esposito, M., Ericson, L.E. and Verbout, A.J. (1998) Integration of PressFit Implants in Cortical Bone: A Study on Interface Kinetics. Journal of Biomedical Materials Research, 41, 574-583. http://dx.doi.org/10.1002/(SICI)1097-4636(19980915)41:4<574::AID-JBM9>3.0.CO;2-9

[7] Slaets, E., Carmeliet, G., Naert, I. and Duyck, J. (2006) Early Cellular Responses in Cortical Bone Healing around Unloaded Titanium Implants: An Animal Study. Journal of Periodontology, 77, 1015-1024. http://dx.doi.org/10.1902/jop.2006.050196

[8] Heimann, R.B. (2013) Structure, Properties, and Biomedical Performance of Osteoconductive Bioceramic Coatings. Surface and Coatings Technology, 233, 27-38. http://dx.doi.org/10.1016/j.surfcoat.2012.11.013

[9] Moroni, A., Caja, V.L., Egger, E.L., Trinchese, L. and Chao, E.Y. (1994) Histomorphometry of Hydroxyapatite Coated and Uncoated Porous Titanium Bone Implants. Biomaterials, 15, 926-930. http://dx.doi.org/10.1016/0142-9612(94)90119-8

[10] Kusakabe, H., Sakamaki, T., Nihei, K., Oyama, Y., Yanagimoto, S., Ichimiya, M., et al. (2004) Osseointegration of a Hydroxyapatite-Coated Multilayered Mesh Stem. Biomaterials, 25, 2957-2969. http://dx.doi.org/10.1016/j.biomaterials.2003.09.090

[11] Hasegawa, M., Sudo, A., Komlev, V.S., Barinov, S.M. and Uchida, A. (2004) High Release of Antibiotic from a Novel Hydroxyapatite with Bimodal Pore Size Distribution. Journal of Biomedical Materials Research, 70, 332-339. http://dx.doi.org/10.1002/jbm.b.30047

[12] Sörensen, T.C., Arnoldi, J., Procter, P., Beimel, C., Jönsson, A., Lennerås, M., et al. (2013) Locally Enhanced Early Bone Formation of Zoledronic Acid Incorporated into a Bone Cement Plug in Vivo. Journal of Pharmacy and Pharmacology, 65, 201-212. http://dx.doi.org/10.1111/j.2042-7158.2012.01588.x

[13] Forsgren, J., Brohede, U., Piscounova, S., Mihranyan, A., Larsson, S., Strømme, M., et al. (2011) In Vivo Evaluation of Functionalized Biomimetic Hydroxyapatite for Local Delivery of Active Agents. Journal of Biomaterials and Nanobiotechnology, 2, 149-154. http://dx.doi.org/10.4236/jbnb.2011.22019

[14] Larsson, S. and Procter, P. (2011) Optimising Implant Anchorage (Augmentation) during Fixation of Osteoporotic Fractures: Is There a Role for Bone-Graft Substitutes? Injury, 42, S72-S76. 
http://dx.doi.org/10.1016/j.injury.2011.06.019

[15] Baker, K., Anderson, M., Oehlke, S., Astashkina, A., Haikio, D., Drelich, J., et al. (2006) Growth, Characterization and Biocompatibility of Bone-Like Calcium Phosphate Layers Biomimetically Deposited on Metallic Substrata. Materials Science and Engineering: C, 26, 1351-1360. http://dx.doi.org/10.1016/j.msec.2005.08.015

[16] Allegrini, S., Rumpel, E., Kauschke, E., Fanghänel, J. and König, B. (2006) Hydroxyapatite Grafting Promotes New Bone Formation and Osseointegration of Smooth Titanium Implants. Annals of Anatomy-Anatomischer Anzeiger, 188, 143-151. http://dx.doi.org/10.1016/j.aanat.2005.08.019

[17] Alt, V., Bitschnau, A., Böhner, F., Heerich, K.E., Magesin, E., Sewing, A., et al. (2011) Effects of Gentamicin and Gentamicin-RGD Coatings on Bone Ingrowth and Biocompatibility of Cementless Joint Prostheses: An Experimental Study in Rabbits. Acta Biomaterialia, 7, 1274-1280. http://dx.doi.org/10.1016/j.actbio.2010.11.012

[18] Cao, N., Dong, J., Wang, Q., Ma, Q., Xue, C. and Li, M. (2010) An Experimental Bone Defect Healing with Hydroxyapatite Coating Plasma Sprayed on Carbon/Carbon Composite Implants. Surface and Coatings Technology, 205, 1150-1156. http://dx.doi.org/10.1016/j.surfcoat.2010.05.008

[19] Sörensen, T.C., Arnoldi, J., Procter, P., Robioneck, B. and Steckel, H. (2013) Bone Substitute Materials Delivering Zoledronic Acid: Physicochemical Characterization, Drug Load, and Release Properties. Journal of Biomaterials Applications, 27, 727-738. http://dx.doi.org/10.1177/0885328211424623

[20] Xue, W., Tao, S., Liu, X., Zheng, X. and Ding, C. (2004) In Vivo Evaluation of Plasma Sprayed Hydroxyapatite Coatings Having Different Crystallinity. Biomaterials, 25, 415-421. http://dx.doi.org/10.1016/S0142-9612(03)00545-3

[21] Zhang, H. and Darvell, B.W. (2011) Morphology and Structural Characteristics of Hydroxyapatite Whiskers: Effect of the Initial Ca Concentration, Ca/P Ratio and pH. Acta Biomaterialia, 7, 2960-2968. http://dx.doi.org/10.1016/j.actbio.2011.03.020

[22] Wang, P., Li, C., Gong, H., Jiang, X., Wang, H. and Li, K. (2010) Effects of Synthesis Conditions on the Morphology of Hydroxyapatite Nanoparticles Produced by Wet Chemical Process. Powder Technology, 203, 315-321. http://dx.doi.org/10.1016/j.powtec.2010.05.023

[23] Mihranyan, A., Forsgren, J., Strømme, M. and Engqvist, H. (2009) Assessing Surface Area Evolution during Biomimetic Growth of Hydroxyapatite Coatings. Langmuir, 25, 1292-1295. http://dx.doi.org/10.1021/la803520k

[24] Brohede, U., Zhao, S., Lindberg, F., Mihranyan, A., Forsgren, J., Strømme, M., et al. (2009) A Novel Graded Bioactive High Adhesion Implant Coating. Applied Surface Science, 255, 7723-7728. http://dx.doi.org/10.1016/j.apsusc.2009.04.149

[25] Brohede, U., Forsgren, J., Roos, S., Mihranyan, A., Engqvist, H. and Strømme, M. (2009) Multifunctional Implant Coatings Providing Possibilities for Fast Antibiotics Loading with Subsequent Slow Release. Journal of Materials Science: Materials in Medicine, 20, 1859-1867. http://dx.doi.org/10.1007/s10856-009-3749-6

[26] Forsgren, J., Svahn, F., Jarmar, T. and Engqvist, H. (2007) Formation and Adhesion of Biomimetic Hydroxyapatite Deposited on Titanium Substrates. Acta Biomaterialia, 3, 980-984. http://dx.doi.org/10.1016/j.actbio.2007.03.006

[27] Ma, J., Wang, C. and Peng, K. (2003) Electrophoretic Deposition of Porous Hydroxyapatite Scaffold. Biomaterials, 24, 3505-3510. http://dx.doi.org/10.1016/S0142-9612(03)00203-5

[28] Liu, D.M., Troczynski, T. and Tseng, W.J. (2001) Water-Based Sol-Gel Synthesis of Hydroxyapatite: Process Development. Biomaterials, 22, 1721-1730. http://dx.doi.org/10.1016/S0142-9612(00)00332-X

[29] Shapiro, S.S. and Wilk, M.B. (1965) An Analysis of Variance Test for Normality Complete Samples. Biometrika, 52, 591-611. http://dx.doi.org/10.1093/biomet/52.3-4.591

[30] Seebeck, J., Goldhahn, J., Morlock, M.M. and Schneider, E. (2005) Mechanical Behavior of Screws in Normal and Osteoporotic Bone. Osteoporosis International, 16, S107-S111. http://dx.doi.org/10.1007/s00198-004-1777-0

[31] Moroni, A., Faldini, C., Marchetti, S., Manca, M., Consoli, V. and Giannini, S. (2001) Improvement of the Bone-Pin Interface Strength in Osteoporotic Bone with Use of Hydroxyapatite-Coated Tapered External-Fixation Pins. A Prospective, Randomized Clinical Study of Wrist Fractures. Journal of Bone and Joint Surgery (American Volume), 83, 717-721.

[32] Caja, V.L. and Moroni, A. (1996) Hydroxyapatite Coated External Fixation Pins: An Experimental Study. Clinical Orthopaedics and Related Research, 325, 269-275. http://dx.doi.org/10.1097/00003086-199604000-00033

[33] Shepperd, J.A.N. and Apthorp, H. (2005) A Contemporary Snapshot of the Use of Hydroxyapatite Coating in Orthopaedic Surgery. Journal of Bone and Joint Surgery (British Volume), 87, 1046-1049. http://dx.doi.org/10.1302/0301-620X.87B8.16692

[34] Piza, G., Caja, V.L., Gonzalez-Viejo, M.A. and Navarro, A. (2004) Hydroxyapatite-Coated External-Fixation Pins. The Effect on Pin Loosening and Pin-Track Infection in Leg Lengthening for Short Stature. Journal of Bone and Joint Surgery (British Volume), 86, 892-897. 
[35] Magyar, G., Toksvig-Larsen, S. and Moroni, A. (1997) Hydroxyapatite Coating of Threaded Pins Enhances Fixation. Journal of Bone and Joint Surgery (British Volume), 79, 487-489. http://dx.doi.org/10.1302/0301-620X.79B3.7190

[36] Yang, G., He, F., Yang, X., Wang, X. and Zhao, S. (2008) Bone Responses to Titanium Implants Surface-Roughened by Sandblasted and Double Etched Treatments in a Rabbit Model. Oral Surgery, Oral Medicine, Oral Pathology, Oral Radiology, and Endodontology, 106, 516-524. http://dx.doi.org/10.1016/j.tripleo.2008.03.017

[37] Yang, G., He, F., Hu, J., Wang, X. and Zhao, S. (2009) Effects of Biomimetically and Electrochemically Deposited Nano-Hydroxyapatite Coatings on Osseointegration of Porous Titanium Implants. Oral Surgery, Oral Medicine, Oral Pathology, Oral Radiology, and Endodontology, 107, 782-789. http://dx.doi.org/10.1016/j.tripleo.2008.12.023

[38] Zhang, E. and Zou, C. (2009) Porous Titanium and Silicon-Substituted Hydroxyapatite Biomodification Prepared by a Biomimetic Process: Characterization and in Vivo Evaluation. Acta Biomaterialia, 5, 1732-1741. http://dx.doi.org/10.1016/j.actbio.2009.01.014

[39] Eom, T., Jeon, G., Jeong, C., Kim, Y., Kim, S., Cho, I., et al. (2012) Experimental Study of Bone Response to Hydroxyapatite Coating Implants: Bone-Implant Contact and Removal Torque Test. Oral Surgery, Oral Medicine, Oral Pathology and Oral Radiology, 114, 411-418. http://dx.doi.org/10.1016/j.0000.2011.10.036

[40] Esposito, M., Hirsch, J.M., Lekholm, U. and Thomsen, P. (1998) Biological Factors Contributing to Failures of Osseointegrated Oral Implants. (I). Success Criteria and Epidemiology. European Journal of Oral Sciences, 106, 527-551. http://dx.doi.org/10.1046/j.0909-8836..t01-2-.X

[41] Yildirim, O., Aksakal, B., Celik, H., Vangolu, Y. and Okur, A. (2005) An Investigation of the Effects of Hydroxyapatite Coatings on the Fixation Strength of Cortical Screws. Medical Engineering \& Physics, 27, 221-228. http://dx.doi.org/10.1016/j.medengphy.2004.10.006

[42] Pieske, O., Kaltenhauser, F., Pichlmaier, L., Schramm, N., Trentzsch, H., Löffler, T., et al. (2010) Clinical Benefit of Hydroxyapatite-Coated Pins Compared with Stainless Steel Pins in External Fixation at the Wrist: A Randomised Prospective Study. Injury, 41, 1031-1036. http://dx.doi.org/10.1016/j.injury.2010.03.030

[43] Sennerby, L., Thomsen, P. and Ericson, L. (1993) Early Tissue Response to Titanium Implants Inserted in Rabbit Cortical Bone. Journal of Materials Science: Materials in Medicine, 4, 240-250. http://dx.doi.org/10.1007/BF00122275

[44] Roshan-Ghias, A., Arnoldi, J., Procter, P. and Pioletti, D.P. (2011) In Vivo Assessment of Local Effects after Application of Bone Screws Delivering Bisphosphonates into a Compromised Cancellous Bone Site. Clinical Biomechanics, 26, 1039-1043. http://dx.doi.org/10.1016/j.clinbiomech.2011.06.004

[45] Mittal, M., Nath, S. and Prakash, S. (2011) Splat Formation and Degradation of Hydroxyapatite during Plasma Spraying Process. Advances in Materials Sciences, 11, 26-36.

[46] Rigo, E., Boschi, A., Yoshimoto, M., Allegrini, S., Konig, B. and Carbonari, M. (2004) Evaluation in Vitro and in Vivo of Biomimetic Hydroxyapatite Coated on Titanium Dental Implants. Materials Science and Engineering: C, 24, 647651. http://dx.doi.org/10.1016/j.msec.2004.08.044

[47] Lilja, M., Sörensen, J.H., Sörensen, T.C., Åstrand, M., Procter, P., Steckel, H., et al. (2013) Impact of Biomechanical Forces on Antibiotics Release Kinetics from Hydroxyapatite Coated Surgical Fixation Pins. Journal of Biomaterials and Nanobiotechnology, 4, 343-350. http://dx.doi.org/10.4236/jbnb.2013.44043

[48] Sörensen, J.H., Lilja, M., Sörensen, T.C., Åstrand, M., Procter, P., Fuchs, S., et al. (2014) Biomechanical and Antibacterial Properties of Tobramycin Loaded Hydroxyapatite Coated Fixation Pins. Journal of Biomedical Materials Research Part B: Applied Biomaterials, 102, 1381-1392. http://dx.doi.org/10.1002/jbm.b.33117

[49] Chan, S., Neu, C., Komvopoulos, K. and Reddi, A. (2011) The Role of Lubricant Entrapment at Biological Interfaces: Reduction of Friction and Adhesion in Articular Cartilage. Journal of Biomechanics, 44, 2015-2020. http://dx.doi.org/10.1016/j.jbiomech.2011.04.015

[50] Peter, B., Pioletti, D.P., Laib, S., Bujoli, B., Pilet, P., Janvier, P., et al. (2005) Calcium Phosphate Drug Delivery System: Influence of Local Zoledronate Release on Bone Implant Osteointegration. Bone, 36, 52-60. http://dx.doi.org/10.1016/j.bone.2004.10.004

[51] Wermelin, K., Suska, F., Tengvall, P., Thomsen, P. and Aspenberg, P. (2008) Stainless Steel Screws Coated with Bisphosphonates Gave Stronger Fixation and More Surrounding Bone. Histomorphometry in Rats. Bone, 42, 365-371. http://dx.doi.org/10.1016/j.bone.2007.10.013 
Scientific Research Publishing (SCIRP) is one of the largest Open Access journal publishers. It is currently publishing more than 200 open access, online, peer-reviewed journals covering a wide range of academic disciplines. SCIRP serves the worldwide academic communities and contributes to the progress and application of science with its publication.

Other selected journals from SCIRP are listed as below. Submit your manuscript to us via either submit@scirp.org or Online Submission Portal.
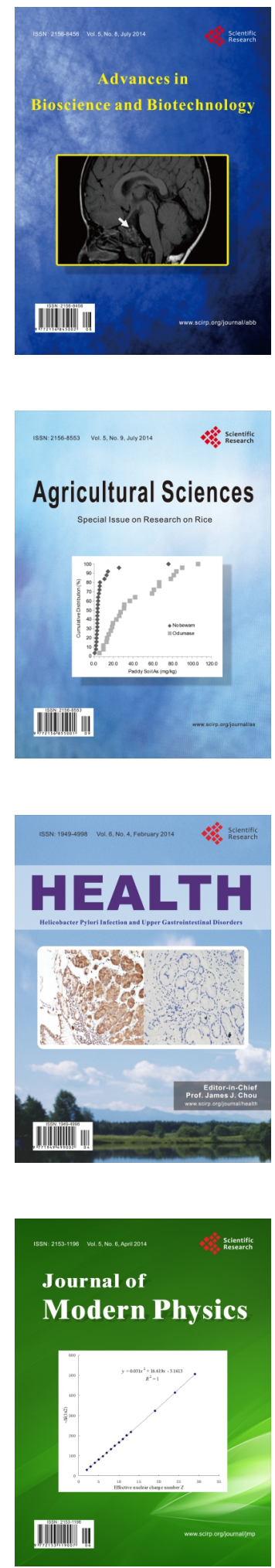
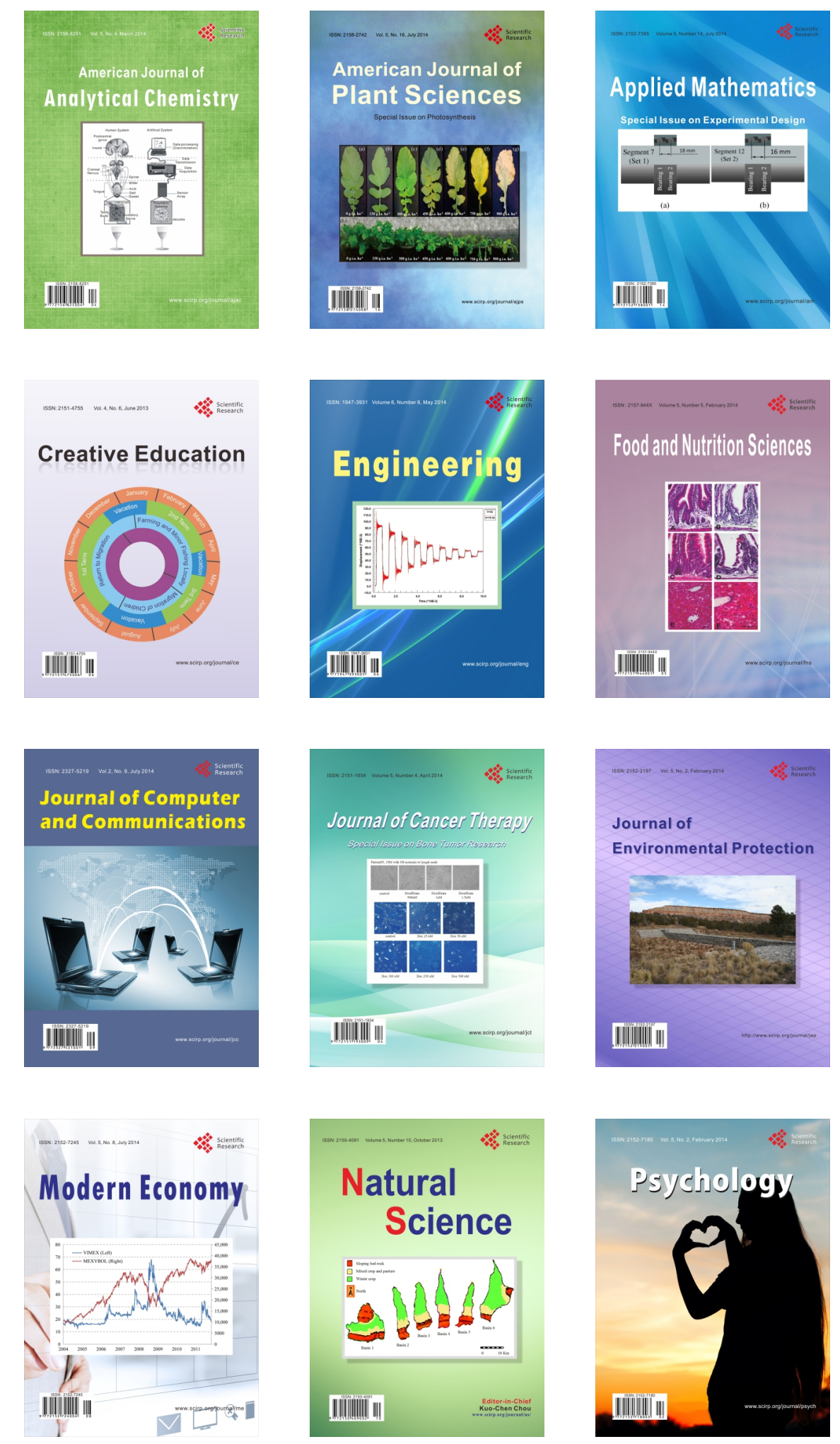